\title{
Correction to: One shot NEPA plus dexamethasone to prevent chemotherapy-induced nausea and vomiting (CINV) in sarcoma patients receiving multiple-day chemotherapy
}

Giuseppe Badalamenti ${ }^{1}$ - Lorena Incorvaia ${ }^{1} \cdot$ Carlo Messina $^{2} \cdot$ Emmanuela Musso $^{1}$ - Alessandra Casarin ${ }^{1}$. Maria Rita Ricciardi ${ }^{1}$ - Ida De Luca ${ }^{1}$. Viviana Bazan ${ }^{3}$. Antonio Russo ${ }^{1}$

Published online: 14 May 2019

(C) Springer-Verlag GmbH Germany, part of Springer Nature 2019

\section{Correction to: Supportive Care in Cancer} https://doi.org/10.1007/s00520-019-4645-3

The title of the original paper is incorrect and is now corrected in this aticle. The correct title is:

One shot NEPA plus dexamethasone to prevent chemotherapy-induced nausea and vomiting (CINV) in sarcoma patients receiving multiple-day chemotherapy

Publisher's note Springer Nature remains neutral with regard to jurisdictional claims in published maps and institutional affiliations.

The online version of the original article can be found at https://doi.org/ $10.1007 / \mathrm{s} 00520-019-4645-3$

Giuseppe Badalamenti

giuseppe.badalamenti@unipa.it

1 Department of Surgical, Oncological and Oral Sciences, Section of Medical Oncology, University of Palermo, Palermo, Italy

2 Medical Oncology Unit, Santa Chiara Hospital, Trento, Italy

3 Department of Experimental Biomedicine and Clinical Neurosciences, School of Medicine, University of Palermo, Palermo, Italy 